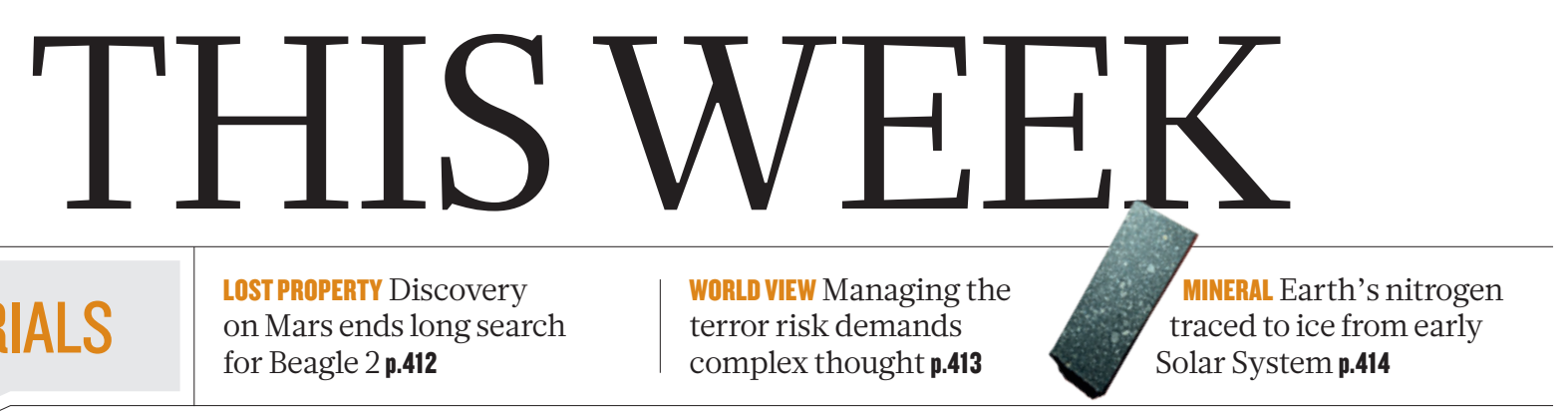

EDITORIALS for Beagle 2 p.412 terror risk demands complex thought $\mathbf{p . 4 1 3}$

\title{
Kept on a leash
}

\section{A vital dependence of genetically modified organisms on an artificial nutrient could be a means of preventing their escape into the environment.}

$\mathrm{O}$ f all the concerns and complaints about the use of genetically modified organisms (GMOs), one of the most legitimate has always been the threat of pollution. Life will, after all, find a way. And genetically altered life is no different. From super-weeds made resistant to herbicides, to contamination of food with genetically modified ingredients, it has proved difficult to keep the technology fully contained.

The risks posed by the unintended spread of GMOs are uncertain, but they are infinitely lower than the nightmare scenarios painted by opponents. Yet in many respects that is beside the point. As this journal has pointed out before, public opinion matters here, whether or not scientists think that the basis for that opinion is misguided. Researchers who would create and release GMOs have a duty - ethical and often statutory or regulatory - to minimize the collateral impact on those who do not share their enthusiasm for the technology. Most, of course, already take that responsibility seriously. But many of the promised benefits of genetic modification, from the development of new fuels and medicines to more-durable crops, demand broad deployment outside the laboratory. And outside the laboratory, things can and do go wrong.

If genetic modification cannot be kept in its box, then can it be kept on a leash? Two papers published this week on Nature's website offer hope that it can be. In principle, the techniques described in the papers could defuse the major concerns about GMO pollution. But, depending on how the science is applied, they could exaggerate some of the separate worries about the social and economic impact that continue to dog the commercial application of genetic modification, in Europe in particular.

The new approach gives GMOs an Achilles heel. The researchers who have produced the organism have built in vital dependency on an artificial nutrient. If the nutrient is withdrawn, or the organism spreads to where it is no longer available, then the organism cannot survive. Pull too tightly on the leash and it turns into a noose.

The research marks an elegant step forward for the growing field of synthetic biology. In the first paper, Farren Isaacs and his colleagues at Yale University in New Haven, Connecticut, describe how they have produced various GMOs whose growth is restricted by the expression of multiple essential genes that depend on synthetic amino acids (A. J. Rovner et al. Nature http://dx.doi.org/10.1038/ nature14095; 2015). In the second, separate study, George Church at Harvard Medical School in Boston, Massachusetts, and his colleagues redesigned essential enzymes in a GMO to make it metabolically dependent on synthetic amino acids (D. J. Mandell et al. Nature http://dx.doi.org/10.1038/nature14121; 2015). The modifications are made throughout the genome to make it harder for the altered sequences to be ejected.

More details of the science are included in a News story on page 423. In both cases, the organisms cannot use alternative nutrients as a supplement when the synthetic amino acids are unavailable, and they seem to be resistant to mutations that improve their survival in the wild, thanks to the multiple sites of genetic modification. In theory, these features make the control of GMOs more effective than with current techniques. The research in both papers is with bacteria, but there seems no reason why the techniques they describe could not be used to engineer more-complex, multicellular organisms - including
"It is important not to gloss over concerns, however irrational they may seem to some."

$$
\text { crops - in the same way. }
$$

So what is the downside? Much of the controversy over genetic modification relates to early, clumsy, attempts by big business to commercialize crops, and to gain control over where, when and how they were grown to maximize profit. A crop that needs constant nourishment with a bespoke foodstuff - unavailable elsewhere and with manufacture protected under probable patents - could be presented as a way of tying vulnerable farmers still closer to largely unloved seed companies.

It is early days, but is it too early to consider such a scenario? Yes and no. As the researchers correctly point out, the technology could most immediately be useful for containing GMOs used in research and industrial systems - microbes typically - to make high-value pharmaceuticals, for example. But applications in crops are some way off.

Still, perceptions matter, and it is important not to gloss over concerns, however irrational they may seem to some. Last week, the European Union agreed on compromise legislation that might settle more than a decade of disagreement and allow research and development on GMOs to proceed (see Nature 516,$143 ; 2014$ ). The new research can address an old fear - contamination - that contributed to the controversy. But it is prudent to consider other anxieties that might sprout in its place.

\section{Down to earth}

\section{A concerted focus on soils will benefit society in untold ways and should be embraced.}

$\mathrm{T}$ The year 2015 carries many titles. For physics fans, it is the International Year of Light, marking 100 years since Albert Einstein developed his general theory of relativity. For development experts, it is the International Year of Evaluation, a time to promote evidence-based policy-making.

But 2015 also bears earthier significance. The Food and Agriculture Organization of the United Nations (FAO) has decreed 